\title{
Caracterização Mecânica e Térmica da Borracha Natural Formulada e Vulcanizada dos Clones: GT 1, IAN 873, PB 235 e RRIM 600
}

\author{
Ana C. Dall'Antonia \\ Interunidades em Ciência e Engenharia de Materiais, USP \\ Embrapa Instrumentação Agropecuária, São Carlos/SP
}

Maria A. Martins, Rogério M. B. Moreno, Luiz H. C. Mattoso Embrapa Instrumentação Agropecuária, São Carlos/SP

Paulo S. Gonçalves Instituto Agronômico, Apta/IAC, Programa Seringueira, Campinas/SP

Aldo E. Job Departamento de Física, Química e Biologia, UNESP/Presidente Prudente/SP

\begin{abstract}
Resumo: Neste trabalho estudou-se o desempenho mecânico e térmico de compostos de borracha natural (Hevea brasiliensis) de 4 diferentes clones (GT 1, IAN 873, PB 235 e RRIM 600) cultivados no Estado de São Paulo, assim como de uma mistura destes clones e de uma borracha comercial, GEB-1. Estas borrachas foram formuladas e vulcanizadas com tempos de 5, 7 e 9 minutos. A caracterização foi realizada por calorimetria exploratória diferencial, termogravimetria, ensaios de resistência à tração, análise dinâmico-mecânica, medidas de dureza Shore A, microscopia eletrônica de varredura e espectroscopia na região do infravermelho. Os resultados permitiram concluir que o tempo de vulcanização e o tipo de clone não influenciaram na temperatura de transição vítrea (Tg) dos compostos. Os valores de Tg obtidos por DMA foram de cerca de $-62{ }^{\circ} \mathrm{C}$, e os resultados ensaios de dureza apresentaram valores próximos de 60 para todos os compostos estudados. Os ensaios de resistência à tração mostraram que o melhor desempenho mecânico foi obtido pelo clone RRIM 600. De acordo com os resultados obtidos neste trabalho, todos os clones atingiram as propriedades reportadas na literatura, podendo ser utilizados, em princípio, nas indústrias de artefatos de borracha separadamente ou na forma de mistura.
\end{abstract}

Palavras-chave: Borracha natural, caracterização, compostos, clones.

\section{Mechanical and Thermal Characterization of Compounds of Natural Rubber of the Clones: GT 1, IAN 873, PB 235 and RRIM 600}

\begin{abstract}
The objective of this work was to study the mechanical and thermal performance of natural rubber (Hevea brasiliensis) compounds of different types of clones (GT 1, IAN 873, PB 235 and RRIM 600), as well as a mixture made from these clones and a commercial rubber GEB-1. These rubbers were formulated and prepared in a two-roll mill and vulcanized at different times (5, 7 and 9 minutes). The evaluation of the mechanical and thermal performance of different natural rubber compounds was carried out by differential scanning calorimetry (DSC), thermogravimetry analysis (TGA), mechanical properties (tensile and hardness tests), dynamic mechanic thermal analysis (DMTA), scanning electron microscopy (SEM), and infrared spectroscopy (FTIR). The values obtained for glass transition temperature ( $\mathrm{Tg}$ ) for vulcanized rubbers were found to be around $-62{ }^{\circ} \mathrm{C}$, while in the hardness test the values obtained were close to 60 , with no great variations when the vulcanization time and type of clone were varied. The tensile tests showed that the best performance was obtained for the clone RRIM 600. All the samples studied were in agreement with standard specifications required for application in the rubber industry, indicating that all clones can be used, in principle, in the rubber industry in blended or unblended forms.
\end{abstract}

Keywords: Natural rubber, clone, compound, characterization.

\section{Introdução}

A pesquisa para a seleção e avaliação dos clones, do látex e da borracha natural é importante para garantir o sucesso da cultura de seringueira. No Brasil, as regiões Sudeste e Centro-Oeste apresentam condições climáticas favoráveis ao desenvolvimento da cultura da seringueira e desfavoráveis ao mal-das-folhas, principal doença que ataca esta cultura. Devido às condições de escape a doenças, ao uso de clones adaptados e produtivos, e ao manejo adequado tem-

Autor para correspondência: Luiz H. C. Mattoso, Embrapa Instrumentação Agropecuária, Caixa Postal 741, CEP: 13560-970, São Carlos, SP, Brasil. 
se constatado o sucesso da heveicultura nessas áreas, responsáveis atualmente por mais de $90 \%$ da produção brasileira de borracha natural ${ }^{[1,2]}$.

Há cerca de 120 anos, quando teve início sua domesticação na Ásia, a seringueira foi considerada mais uma espécie selvagem da Amazônia. A partir desse período, o melhoramento genético tem contribuído para seu desenvolvimento, elevando o nível da produção de $400 \mathrm{~kg}$ para $2.500 \mathrm{~kg} / \mathrm{ha} / \mathrm{ano}$ de borracha seca. Hibridações seletivas entre clones superiores de seringueira, seguidas da multiplicação vegetativa do ortete selecionado e posterior avaliação, têm sido a base do melhoramento genético no Estado de São Paulo ${ }^{[3,4]}$.

Um clone é formado por um grupo de plantas obtidas através da propagação vegetativa de uma planta matriz, e todas as árvores de um clone possuem a mesma constituição genética, responsável por sua uniformidade ${ }^{[5]}$. O termo clone é empregado porque as variedades selecionadas são propagadas por enxertia, que é um dos métodos de clonagem de plantas, possibilitando a formação de plantações uniformes, com bom desenvolvimento, alta produtividade e outras características de interesse. Em geral, os clones recebem o nome da instituição de origem, sob forma de sigla, seguido após um espaço, de um número de série designado pelo melhorista responsável ${ }^{[6]}$. A borracha da Hevea brasiliensis é um polímero de alta massa molar, essencialmente composta de poli (cis-1,4-isopreno), na qual as unidades repetitivas da molécula são arranjadas na configuração cabeça-cauda ${ }^{[7]}$.

A formulação e a vulcanização com outros constituintes ou aditivos da borracha natural crua é que a torna aplicável para a maioria dos processos industriais, e ao resultado desta mistura é dado o nome de composto de borracha. Através da vulcanização consegue-se transformar as propriedades plásticas da borracha, eliminar sua sensibilidade ao calor e obter um corpo elástico capaz de retomar suas dimensões primitivas depois de uma deformação, mesmo em condições extremas de temperatura ${ }^{[8-12]}$.

Vários estudos sobre a influência do processamento e dos componentes para formulação nas propriedades da borracha natural, tais como a combinação de dois aceleradores para aumentar a segurança durante o processo ${ }^{[13]}$, a variação da temperatura de transição vítrea $(\mathrm{Tg})$ em função do conteúdo de negro de fumo ${ }^{[14]}$, a utilização das cinzas de cascas do arroz como carga em comparação com outras cargas comerciais, como talco, argila, carbonato do cálcio, sílica e o negro de fumo ${ }^{[15,16]}$, a influência dos parâmetros de mistura em misturador aberto (diferença de velocidade dos cilindros, a razão de fricção entre os mesmos e a quantidade de massa do composto $)^{[17]}$, são relatados na literatura. Entretanto, a avaliação das propriedades tecnológicas da borracha formulada e vulcanizada de diferentes clones visando à melhoria da qualidade do látex e da borracha natural nacional tem sido pouco investigada $^{[1]}$.

O objetivo deste trabalho foi investigar o desempenho mecânico e térmico de borracha natural formulada e vulcanizada de diferentes clones (GT 1, IAN 873, PB 235 e RRIM 600) recomendados para o plantio em larga escala no Estado de São Paulo. A avaliação foi realizada através de ensaios de resistência à tração, análise dinâmico-mecânica (DMA), calorimetria exploratória diferencial (DSC), termogravimetria (TG), dureza Shore A, microscopia eletrônica de varredura (MEV) e espectroscopia na região do infravermelho (FTIR).

\section{Experimental}

\section{Materiais}

Amostras de látex de borracha natural de quatro clones foram coletadas no Pólo Regional Noroeste Paulista, município de Votuporanga/SP. Os clones estudados foram: RRIM 600 (Rubber Research Institute of Malaysia); GT 1 (Gondang Tapen); IAN 873 (Instituto Agronômico do Norte); PB 235 (Prang Besar). As sangrias foram realizadas em árvores que possuiam circunferência do caule igual ou superior a $45 \mathrm{~cm}$ a 1,20 m de altura do calo de enxertia, utilizando o sistema $1 / 2 \mathrm{~S} \mathrm{~d} / 46 \mathrm{~d} / 7$ (corte em meio espiral, sangradas quatro vezes por semana, estimuladas com Ethrel por pincelamento do painel de sangria a cada 45 dias).

A borracha natural comercialmente estabelecida no mercado nacional utilizada foi do tipo GEB-1 (Granulado-Escuro-Brasileiro). Esta borracha é obtida nas usinas de beneficiamento a partir de coagulados diversos de diferentes clones, sendo em geral, provenientes de diferentes produtores. Foi fornecida pela Indústria de borracha Top Color localizada em São Carlos-SP.

Para a formulação da borracha natural foram utilizados: o antioxidante Banox, os aceleradores disulfeto de mercaptobenzotiazol (MBTS) e o dissulfeto de tetrametil tiuram (TMTD), e os aditivos: óxido de zinco, ácido esteárico, óleo de processamento e enxofre fornecidos pela indústria Top Color localizada em São Carlos-SP. Todos os aditivos foram usados sem tratamento prévio, na quantidade indicada na Tabela 1.

Tabela 1. Composição para a formulação da borracha natural.

\begin{tabular}{lc}
\hline \multicolumn{1}{c}{ Componentes } & Quantidade (pcr) \\
\hline Borracha natural & 100 \\
Ácido esteárico & 2 \\
Óxido de zinco & 5 \\
Antioxidante (Banox) & 1 \\
Negro de fumo & 30 \\
Óleo de processamento & 5 \\
M.B.T.S.* & 2 \\
T.M.T.D.** & 1 \\
Enxofre & 2,5 \\
\hline *Disulfeto de mercaptobenzotiazol; e $* *$ dissulfeto de tetrametil \\
tiuram.
\end{tabular}




\section{Métodos}

Após a coleta, o látex dos diferentes clones foi estabilizado com amônia (4,7 mL NH $\mathrm{NH}_{4} \mathrm{OH}$ para cada $100 \mathrm{~mL}$ de látex). O látex coletado foi coagulado pela adição de solução de ácido acético $3 \mathrm{~mol} / \mathrm{L}$. Os coágulos obtidos passaram por uma etapa de lavagem para remoção do ácido acético residual e em seguida foram laminados em um moinho aberto de dois rolos até uma espessura entre $2-3 \mathrm{~mm}$, e secos em estufa à temperatura de cerca de $50{ }^{\circ} \mathrm{C}$ por 24 horas.

O processamento para a formulação da borracha foi realizado em um moinho aberto de dois rolos marca Parabor modelo EQ-ML. As condições de processamento foram: temperatura de $70{ }^{\circ} \mathrm{C}$, velocidade de rotação de $75 \mathrm{rpm}$ e tempo de mistura de 15 minutos. A mistura com $25 \%$ em massa de cada um dos clones, foi homogeneizada em um moinho aberto de dois rolos por cerca de 5 minutos. Após a formulação (Tabela 1) realizou-se moldagem por compressão a temperatura de $145^{\circ} \mathrm{C}$ e pressão de $4 \mathrm{MPa}$, em uma prensa Schwing Siwa, durante 5,7 e 9 minutos.

Para as medidas de calorimetria exploratória diferencial (DSC) utilizou-se um instrumento marca Netzsch DSC 204, com razão de aquecimento de $10{ }^{\circ} \mathrm{C} / \mathrm{min}$ em atmosfera de nitrogênio, na faixa de -90 a $-20{ }^{\circ} \mathrm{C}$, e massa de amostra de cerca de 5,0 mg.

Os ensaios de termogravimetria (TG) foram realizados em um equipamento Netzsch TG 209, com início à temperatura ambiente até $500{ }^{\circ} \mathrm{C}$, a razão de aquecimento de $10^{\circ} \mathrm{C} / \mathrm{min}$, em atmosfera de nitrogênio com fluxo de $15 \mathrm{~mL} / \mathrm{min}$.

A análise dinâmico-mecânica (DMA) foi realizada em um equipamento Netzsch modelo DMTA 242C, no modo de tensão à tração, a frequiência de $10 \mathrm{~Hz}$, com razão de aquecimento de $5{ }^{\circ} \mathrm{C} / \mathrm{min}$, e o intervalo de temperatura de $-100{ }^{\circ} \mathrm{C}$ a $100{ }^{\circ} \mathrm{C}$, em corpos de prova de $10 \times 6 \times 3 \mathrm{~mm}$.

Os ensaios de tração foram realizados segundo a ASTM D 412-97, Método $A^{[18]}$, em um equipamento marca Instron, a velocidade de $500 \mathrm{~mm} / \mathrm{min}$. com célula de carga de $500 \mathrm{~N}$. A dureza foi determinada em durômetro do tipo Shore A, segundo a norma ASTM D 2240-97 $7^{[19]}$.

Amostras com dimensões de $50 \times 50 \times 3 \mathrm{~mm}$ foram analisadas por refletância total atenuada na região do infravermelho (FTIR/ATR) em um equipamento Bruker modelo Vector22.

A microscopia eletrônica de varredura (MEV) foi realizada em um microscópio eletrônico marca ZEISS modelo DSM 960, com feixe de elétrons de $20 \mathrm{kV}$. As amostras foram fraturadas após imersão em nitrogênio líquido. Sobre as amostras depositou-se uma camada de $20 \mathrm{~nm}$ de ouro utilizando-se o equipamento "sputter coater" marca BALZERS modelo SCD 50.

\section{Resultados e Discussão}

Os resultados para os ensaios mecânicos de resistência à tração, deformação e módulo para os tempos de vulcanização de 5, 7 e 9 minutos. são apresentados na Tabela 2.
Com exceção dos compostos do clone GT 1, todos os demais apresentaram, no geral, melhores resultados de resistência à tração e deformação na ruptura para o tempo de vulcanização igual a 5 minutos. Observou-se também que não ocorreu variação significativa no desempenho em relação ao módulo elástico com o aumento do tempo de vulcanização de 5 para 9 minutos. A Figura 1 apresenta como exemplo, as curvas de tensão versus deformação para os compostos do clone RRIM 600 em função do tempo de vulcanização. Com o aumento do tempo de vulcanização houve um decréscimo nos valores de tensão de ruptura e deformação para a maioria das amostras dos compostos de borracha natural. Na temperatura utilizada para a vulcanização dos compostos, que neste caso foi de $145{ }^{\circ} \mathrm{C}$, ocorrem reações competitivas de cisão de cadeia e formação de ligações cruzadas em função do aumento do tempo, que influenciam no comportamento mecânico do material.

Para borrachas vulcanizadas somente com enxofre, a literatura relata valores de resistência à tração entre 17 a $25 \mathrm{MPa}$ e para o módulo de Young de 1,3 $\mathrm{MPa}^{[20]}$, e de acordo com Oliveira e Soares ${ }^{[21]}$ os valores de resistência à tração na ruptura não são influenciados pelo sistema de vulcanização MBTS e TMTD empregados como aceleradores no processo de vulcanização. Os autores observaram que o uso de aceleradores não influencia nos resultados mecânicos, e que a combinação de 2 aceleradores é sinérgica, ou seja, um acelerador ativa o outro, obtendo-se melhores velocidades de formação de ligações cruzadas. A partir dos resultados vê-se que o desempenho dos clones em estudo está, em média, dentro dos valores reportados na literatura para a resistência à tração e acima em relação ao módulo. Como o módulo de Young está diretamente relacionado com a rigidez do polímero, os resultados indicam que as borrachas dos diferentes clones estudados têm rigidez comparável.

A Figura 2 mostra as curvas do módulo de armazenamento (E') e de tan delta da borracha natural crua (borracha in natura, ou seja, sem qualquer aditivo), e dos compostos para a mistura que foi processada utilizando-se $25 \%$ de massa dos clones GT 1, IAN 873, PB 235 e RRIM 600 com diferentes tempos de vulcanização (5, 7 e 9 minutos). As misturas vulcanizadas a 5 e 7 minutos apresentaram melhor desempenho em relação ao módulo do que a mistura vulcanizada a 9 minutos. A borracha natural crua apresentou um valor de módulo bem abaixo do encontrado para os compostos vulcanizados até cerca de $-50{ }^{\circ} \mathrm{C}$, a partir desta temperatura a diminuição no valor do módulo é maior para os compostos. Estes resultados indicam que o negro de fumo, atuou como reforço para a matriz de borracha natural, melhorando suas propriedades mecânicas como módulo elástico e a resistência à tração, sem, no entanto perder significativamente em alongamento. O mesmo comportamento foi obtido para todos os clones. A mobilidade molecular do polímero diminui com o aumento do conteúdo de carga (negro de fumo), devido à formação de ligações físicas entre as partículas da carga e as cadeias do polímero ${ }^{[9]}$. A Figura $2 b$ apresenta as curvas de 
Tabela 2. Valores de resistência à tração na ruptura $(\sigma)$, deformação $(\varepsilon)$ e módulo elástico (E) para amostras de borracha natural com tempo de vulcanização de 5,7 e 9 minutos.

\begin{tabular}{lcccc}
\hline Amostra & $\begin{array}{c}\text { Tempo de vulcanização } \\
\text { (minutos) }\end{array}$ & Tensão na ruptura (MPa) & Deformação na ruptura (\%) & Módulo elástico (MPa) \\
\hline GT 1 & 5 & $14 \pm 6$ & $863 \pm 252$ & $2,1 \pm 0,4$ \\
& 7 & $16 \pm 2$ & $978 \pm 91$ & $2,3 \pm 0,1$ \\
& 9 & $13 \pm 7$ & $852 \pm 311$ & $2,1 \pm 0,5$ \\
\hline IAN 873 & 5 & $16 \pm 2$ & $995 \pm 77$ & $2,4 \pm 0,1$ \\
& 7 & $15 \pm 4$ & $902 \pm 178$ & $2,3 \pm 0,3$ \\
& 9 & $17 \pm 4$ & $972 \pm 147$ & $2,3 \pm 0,2$ \\
\hline PB 235 & 5 & $17 \pm 2$ & $1095 \pm 82$ & $2,1 \pm 0,4$ \\
& 7 & $14 \pm 5$ & $942 \pm 278$ & $2,0 \pm 0,2$ \\
\hline RRIM 600 & 9 & $13 \pm 2$ & $902 \pm 104$ & $2,6 \pm 0,4$ \\
& 5 & $22 \pm 2$ & $1224 \pm 131$ & $2,5 \pm 0,1$ \\
& 7 & $21 \pm 2$ & $1130 \pm 89$ & $2,3 \pm 0,4$ \\
\hline Mistura & 9 & $15 \pm 5$ & $868 \pm 221$ & $2,4 \pm 0,1$ \\
& 5 & $18 \pm 2$ & $1067 \pm 91$ & $2,1 \pm 0,2$ \\
& 7 & $14 \pm 3$ & $888 \pm 156$ & $2,0 \pm 0,2$ \\
\hline Comercial & 9 & $12 \pm 3$ & $773 \pm 116$ & $2,6 \pm 0,1$ \\
& 5 & $20 \pm 2$ & $1147 \pm 58$ & $2,3 \pm 0,2$ \\
& 7 & $16 \pm 3$ & $989 \pm 128$ & $1,9 \pm 0,5$ \\
\hline
\end{tabular}

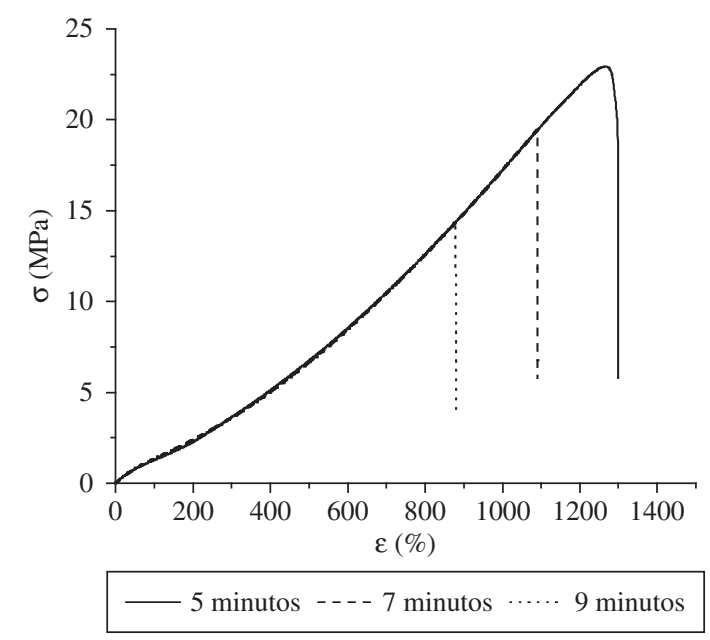

Figura 1. Gráfico de tensão $(\sigma)$ vs. deformação $(\varepsilon)$ para os compostos de borracha natural do clone RRIM 600 para tempos de vulcanização de 5, 7 e 9 minutos.

$\tan \delta$ em função da temperatura, para os compostos vulcanizados a 5,7 e 9 minutos com a mistura. Todas as curvas dos compostos apresentaram perfil semelhante e observa-se que para a mistura dos 4 clones ocorreu aumento da temperatura de transição vítrea ( $\mathrm{Tg}$ ) com a diminuição do tempo de vulcanização. Esta correlação entre o tempo de vulcanização e a Tg não foi observada para todos os clones. Martins e colaboradores ${ }^{[22]}$ verificaram que a adição de celulose regenerada, que é utilizada como carga, promove um afastamento entre as cadeias macromoleculares da borracha, o que acarreta sua maior flexibilidade, e, portanto, menor $\mathrm{Tg}$, o que não foi observado para a incorporação de negro de fumo, caso em que, neste estudo foi observado um aumento no valor da
Tg em relação à borracha crua. Comportamento similar foi observado para os outros clones estudados. O negro de fumo é uma carga reforçadora, e tem grande interação com a matriz elastomérica, influenciando diretamente no desempenho das propriedades, como comentado anteriormente.

Analisando-se a largura dos picos de $\tan \delta$ das amostras, Figura $2 b$, pode-se observar que os compostos apresentaram picos mais estreitos do que o da borracha crua, indicando homogeneidade, ou seja, boa dispersão das partículas de negro de fumo ${ }^{[23]}$. O efeito do negro de fumo nas propriedades dinâmico-mecânicas é função principalmente do estado de dispersão, tanto em relação ao tamanho e número de partículas, quanto da distância de separação entre eles e sua distribuição ${ }^{[20]}$. Pode-se afirmar com base nos dados obtidos neste estudo, que mesmo com tempos de vulcanização de 5,7 e 9 minutos e com diferentes clones, o comportamento dinâmico-mecânico dos compostos não varia significativamente, e que todos os clones atendem ao requisito de temperatura de transição vítrea baixa que é necessário para várias aplicações da borracha natural.

Para o tempo de vulcanização igual a 5 minutos, as curvas do log do módulo de armazenamento (E') e do fator amortecimento $(\tan \delta$ ) são mostradas na Figura 3. Materiais com alto amortecimento dissipam muito da energia que foi utilizada para deformá-lo na forma de calor. Os materiais poliméricos apresentam componente elástica e plástica, sendo o módulo de armazenamento relativo à componente elástica. Observase na Figura 3a que a mistura dos 4 clones e a borracha comercial apresentam um módulo ligeiramente superior que os clones separadamente, sendo o tempo de vulcanização igual para todos ( 5 minutos). Observou-se também, que as curvas não diferem significativamente nos valores de intensidades 


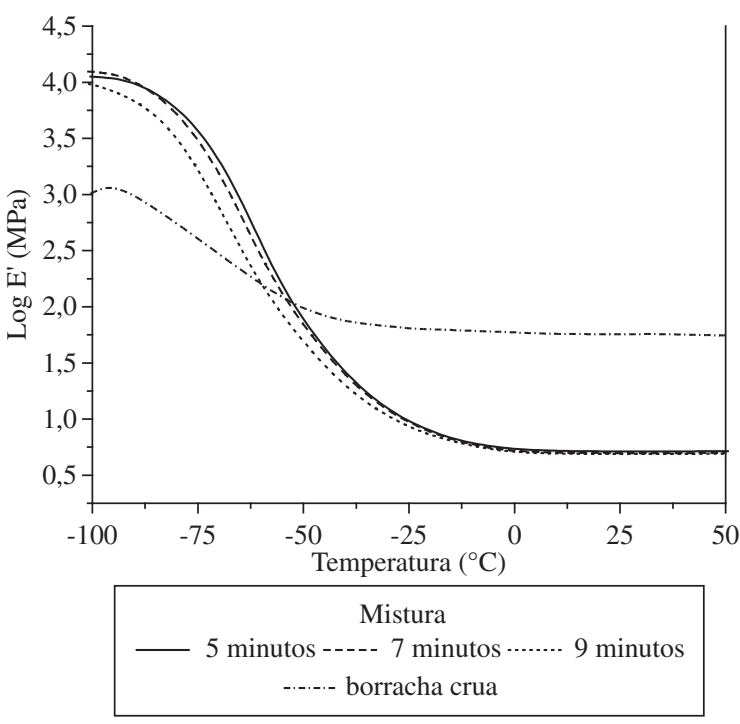

(a)

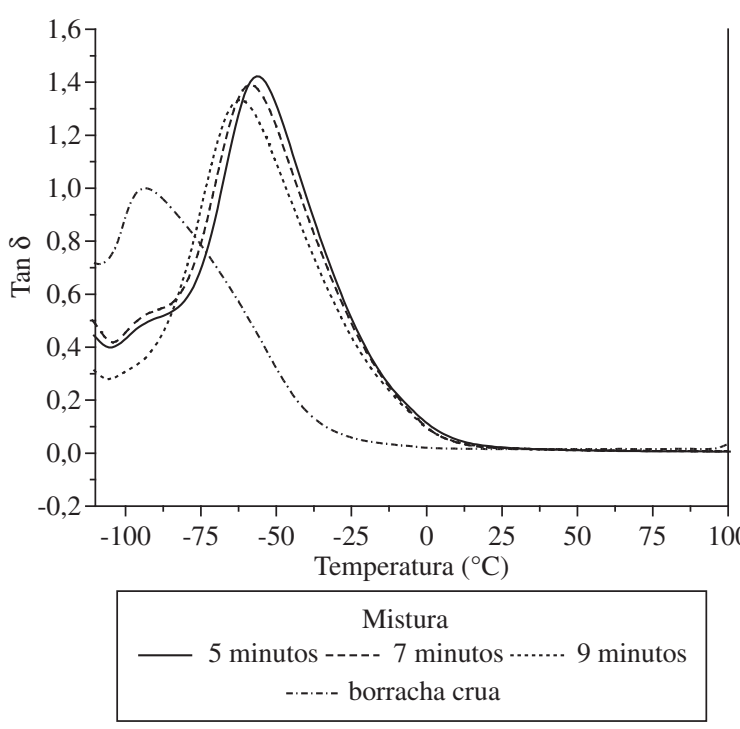

(b)

Figura 2. a) Curvas do log módulo de armazenamento (E'); e b) curvas do fator amortecimento $(\tan \delta) v s$. temperatura para a borracha crua e os compostos da mistura dos 4 clones vulcanizados nos tempos de vulcanização de 5,7 e 9 minutos.

dos máximos de $\tan \delta$ e da $\mathrm{Tg}$, em relação aos diferentes clones no mesmo tempo de vulcanização, Figura 3b. Em relação a $\tan \delta$, pode-se notar que o clone RRIM 600 é o que possui a maior intensidade e o clone GT 1, a menor. Para o tempo de vulcanização igual a 5 minutos, os compostos da borracha comercial e da mistura apresentaram a menor e a maior $\mathrm{Tg}$, -65 e $-57^{\circ} \mathrm{C}$, respectivamente, como se observa na Tabela 3.

A Figura 4 apresenta as curvas DSC do composto da borracha comercial em diferentes tempos de vulcanização e as curvas dos compostos dos clones GT 1, IAN 873, PB 235 e RRIM 600, assim como da mistura dos 4 clones e da borracha comercial, com tempo de vulcanização de 5 minutos. As amostras mostraram comportamento similar e observou-se que não houve mudanças significativas para os valores da $\mathrm{Tg}$

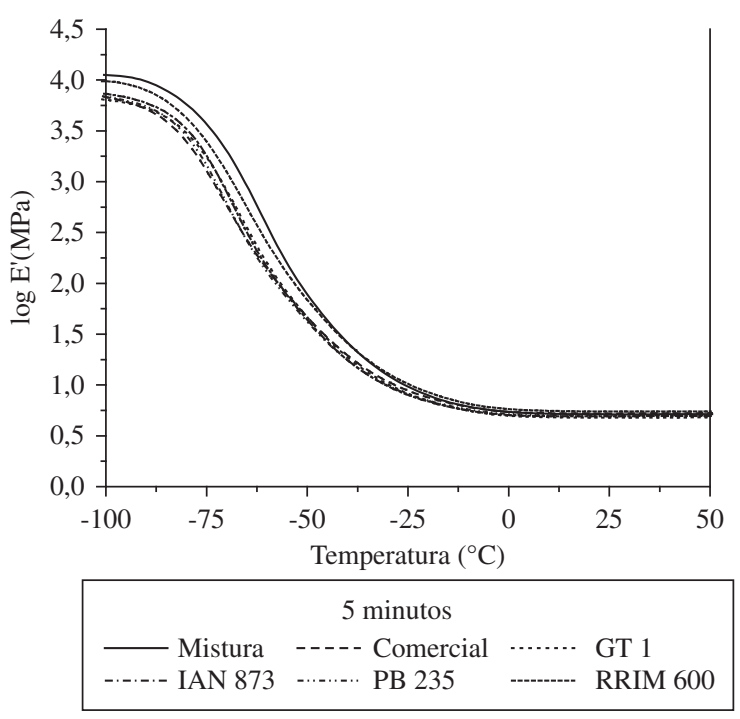

(a)

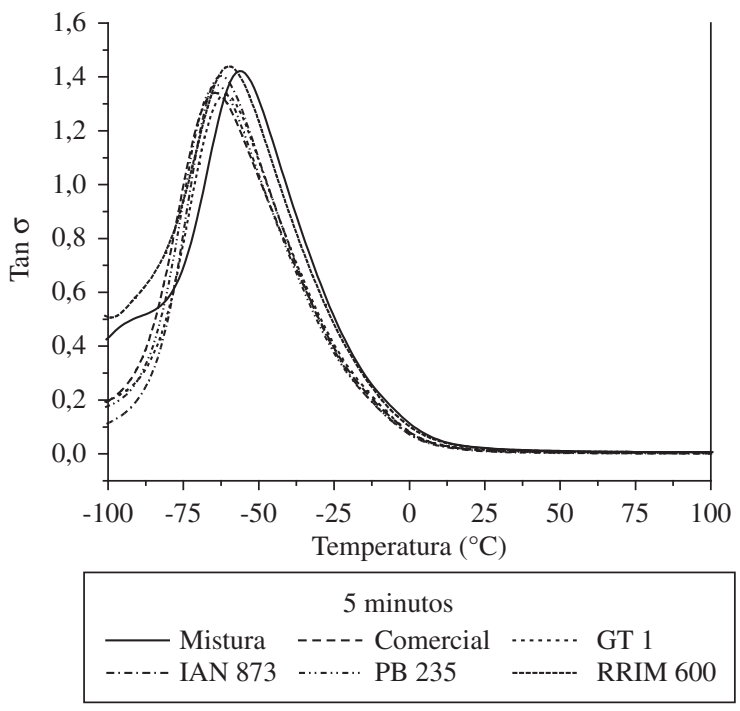

(b)

Figura 3. a) Curvas do log módulo de armazenamento (E'); e b) curvas do fator amortecimento $(\tan \delta) v s$. a temperatura das amostras: GT 1, IAN 873, PB 235, RRIM 600, mistura dos 4 clones, e a borracha comercial, com tempo de vulcanização de 5 minutos.

entre os diferentes clones para as borrachas vulcanizadas a 5 minutos, (Tabela 3). O mesmo comportamento foi obtido para os tempos de 7 e 9 minutos. Comparando-se as curvas obtidas pela análise de DSC para a borracha comercial com diferentes tempos de vulcanização de 5, 7 e 9 minutos, observou-se também que não houve uma grande variação nos valores da $\mathrm{Tg}$, como mostrado na Tabela 3 , em função do tempo de vulcanização e do tipo de clone.

A temperatura de transição vítrea $(\mathrm{Tg})$ refere-se ao intervalo de temperatura na qual o material polimérico muda de um estado vítreo (mais rígido) para um estado mais borrachoso (elastomérico). Abaixo da faixa de transição há relativamente pouca movimentação molecular e os segmentos da cadeia estão como que congelados, sendo capazes de vibrar 
nessas posições fixas, mas com poucas chances de rearranjos nas posições. Aumentando-se a temperatura, a amplitude das vibrações torna-se maior e é possível a movimentação ocasional de segmentos da cadeia. Quanto mais flexível a cadeia, mais baixa a temperatura na qual isto irá ocorrer ${ }^{[24]}$. A Tg obtida através da técnica de calorimetria exploratória

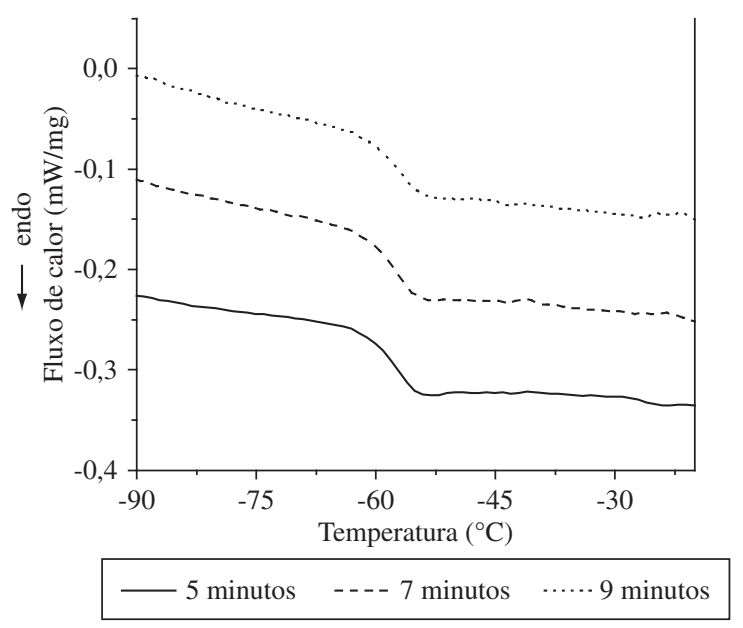

(a)

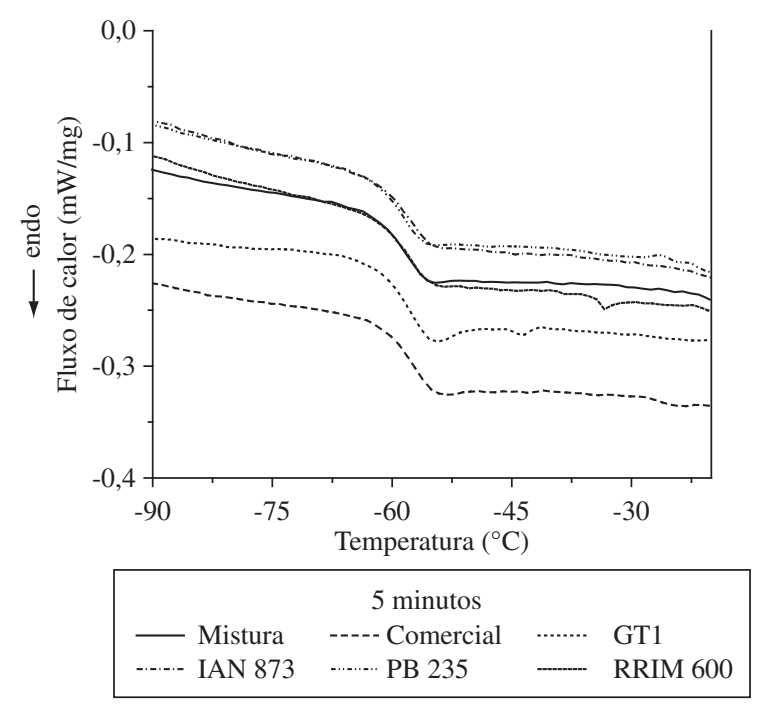

(b)

Figura 4. a) Curvas de DSC do composto da borracha comercial em diferentes tempos de vulcanização; e b) curvas de DSC dos compostos dos clones GT 1, IAN 873, PB 235 e RRIM 600, da mistura dos 4 clones e da borracha comercial, com tempo de vulcanização de 5 minutos. diferencial (DSC) é acompanhada de uma mudança na capacidade de calor, mas não há mudança de entalpia $(\Delta H=0)$. A transição aparece, portanto, como uma descontinuidade na linha de base ${ }^{[25]}$.

Estudos envolvendo as propriedades dinâmico-mecânicas da borracha natural vulcanizada sugerem que mudanças significativas na $\mathrm{Tg}$ podem ser decorrência da formação de grupos heterocíclicos ao longo da cadeia elastomérica ${ }^{[26]}$. Este fenômeno contribui para uma redução da mobilidade molecular da cadeia polimérica. As diferenças nos valores da $\mathrm{Tg}$ encontradas neste estudo não devem ser atribuídas apenas às diferenças no grau de reticulação, mas também a outras interações intra ou intermolecular, que podem variar de acordo com o tempo de vulcanização empregado e tipo de clone. As temperaturas de transição vítrea ( $\mathrm{Tg}$ ) obtidas através do DMA, foram medidas nos pontos máximos das curvas do fator de amortecimento em função da temperatura, e as de DSC através da primeira derivada da curva, sendo que os valores da Tg obtidos pelas técnicas de DSC e DMA, para as amostras dos compostos encontram-se na Tabela 3.

Os valores das temperaturas de transição vítrea da borracha natural crua e da borracha vulcanizada encontradas na literatura são de -72 e de $-63{ }^{\circ} \mathrm{C}^{[2,27]}$, respectivamente. Há um aumento da $\mathrm{Tg}$ depois da vulcanização pelo fato da borracha adquirir uma estrutura reticulada devido à formação de ligações cruzadas pelo enxofre, aumentando o valor da $\mathrm{Tg}$. As ligações cruzadas ligam uma cadeia a outras impedindo sua livre movimentação. Conforme comentado anteriormente, no caso dos elastômeros vulcanizados, o número de ligações cruzadas é baixo.

As temperaturas de transição vítrea obtidas através da técnica de DMA estão em um intervalo de -57 a $-66^{\circ} \mathrm{C}$, sem uma tendência clara de variação em relação ao tipo de clone nem ao tempo de vulcanização. A técnica de DSC tem menor sensibilidade para a determinação de $\mathrm{Tg}$ e os resultados obtidos estão dentro de um intervalo de variação menor, isto é de -57 a $-59^{\circ} \mathrm{C}$, estando dentro do erro experimental, não sendo, portanto, significativa.

O estudo por termogravimetria foi realizado para avaliar a estabilidade térmica da borracha natural crua e dos compostos de borracha natural dos diferentes clones. A Figura 5 apresenta as curvas TG do composto do clone PB 235 em diferentes tempos de vulcanização e as curvas dos compostos dos clones GT 1, IAN 873, PB 235 e RRIM 600, assim como

Tabela 3. Valores da temperatura de transição vítrea (Tg) obtidos através das técnicas de DSC e DMA, para as amostras de borracha natural vulcanizadas com diferentes tempos de vulcanização.

\begin{tabular}{lcccccc}
\hline \multirow{2}{*}{ Amostra } & \multicolumn{2}{c}{$\mathbf{5}$ minutos } & \multicolumn{2}{c}{ 7 minutos } & \multicolumn{3}{c}{ 9 minutos } \\
\cline { 2 - 7 } & DMA & DSC & DMA & DSC & DMA & DSC \\
\hline GT1 & -61 & -58 & -58 & -59 & -63 & -58 \\
IAN 873 & -63 & -58 & -61 & -58 & -59 & -57 \\
PB 235 & -64 & -59 & -62 & -58 & -62 & -57 \\
RRIM 600 & -60 & -57 & -63 & -58 & -64 & -58 \\
Mistura & -57 & -58 & -57 & -58 & -62 & -57 \\
Comercial & -65 & -57 & -66 & -58 & -61 & -57 \\
\hline
\end{tabular}




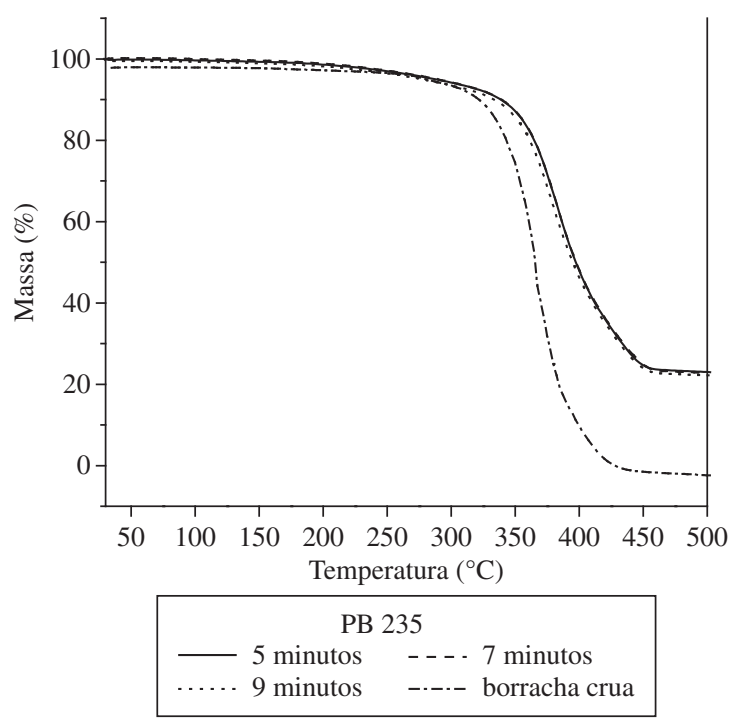

(a)

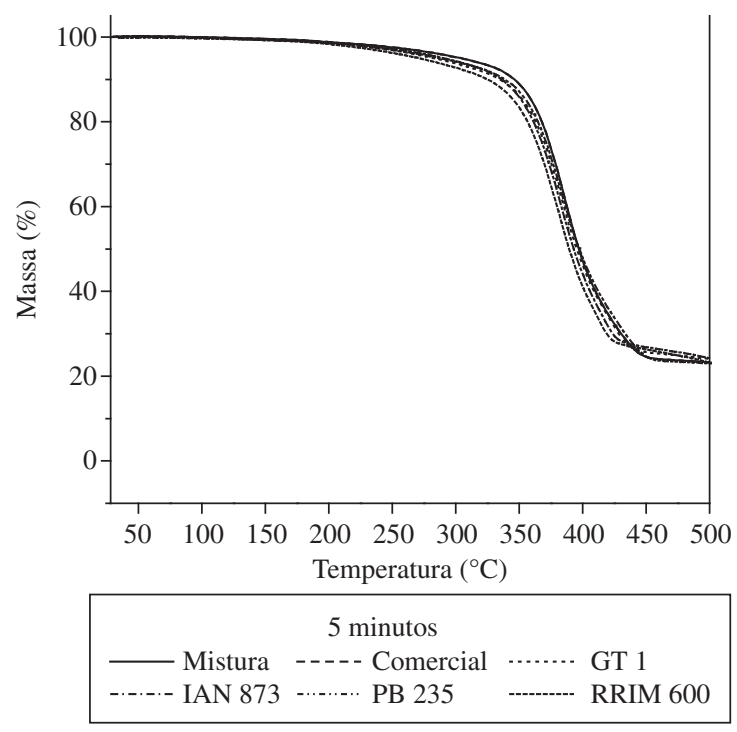

(b)

Figura 5. a) Curvas TG do composto PB 235 em diferentes tempos de vulcanização; e b) curvas TG dos compostos dos clones GT 1, IAN 873, PB 235 e RRIM 600, da mistura e da borracha comercial, com tempo de vulcanização de 5 minutos.

da mistura dos 4 clones e da borracha comercial, com tempo de vulcanização de 5 minutos. Pode-se notar que as amostras com tempo de vulcanização de 5 minutos tiveram o mesmo comportamento, o que também ocorreu para os tempos de vulcanização de 7 e 9 minutos. Para diferentes tempos de vulcanização os clones possuem a mesma perda de massa, restando uma massa residual em torno de $20 \%$, ou seja, 30 pcr o que equivale ao negro de fumo adicionado nos compostos de borracha natural. A amostra da borracha crua apresentou maior perda de massa, devido à ausência de aditivos (negro de fumo, enxofre, antioxidante). Todos os compostos de borracha natural apresentaram uma perda de massa de aproximadamente $2 \%$ até cerca de $230{ }^{\circ} \mathrm{C}$. A perda de massa vai se acentuando e em torno de aproximadamente $300{ }^{\circ} \mathrm{C}$ começa a degradação estrutural da borracha, que perde cerca de $50 \%$ de massa até a temperatura de $360{ }^{\circ} \mathrm{C}$. Não foi observada diferença significativa entre as amostras analisadas, ou seja, os diferentes clones e o controle, o clone RRIM 600 e nem em relação à borracha comercial e a mistura dos 4 clones.

A Figura 6 apresenta os espectros de FTIR dos compostos de borracha natural dos diferentes clones com o tempo de vulcanização de 5 minutos. As atribuições correspondentes às principais bandas são: em $2960 \mathrm{~cm}^{-1}$, banda de estiramento da ligação C-H do carbono olefínico. Na região de 2920 e $2850 \mathrm{~cm}^{-1}$, encontra-se o estiramento assimétrico e simétrico do grupo metila ${ }^{[28,29]}$. Na região de 1450 e $1380 \mathrm{~cm}^{-1}$, encontra-se a deformação angular assimétrica e simétrica do grupo metila, na região de $1540 \mathrm{~cm}^{-1}$, observa-se um estiramento da ligação $\mathrm{C}=\mathrm{C}$, e finalmente na região de $800 \mathrm{~cm}^{-1}$, esta banda é atribuída à flexão da ligação $\mathrm{C}-\mathrm{H}$ em olefina trissubstituída típica do encadeamento cis-1,4. A região entre 1315 e $870 \mathrm{~cm}^{-1}$, tem sido objeto de discussão, as bandas 1250,1100 e $1020 \mathrm{~cm}^{-1}$ são atribuídas respectivamente à deformação angular fora do plano e fora de fase do grupo metilênico, deformação axial da ligação $\mathrm{C}-\mathrm{CH}_{2}$ no plano ${ }^{[28,29]}$. Como esperado, todos os compostos apresentaram as bandas correspondestes ao poli (cis-1,4-isopreno), não sendo observada nenhuma diferença significativa em relação aos grupamentos químicos presentes nos diferentes clones.

A dureza está associada à quantidade de ligações cruzadas formadas durante o processo de vulcanização, sendo também diretamente afetada pela quantidade de enxofre e negro de fumo presente ${ }^{[30]}$. Neste estudo foram utilizados 2,5 e 30 pcr de enxofre e negro de fumo, respectivamente. A Tabela 4 apresenta os resultados obtidos, vê-se que o tempo de vulcanização não tem efeito significativo na dureza dos compostos. Observa-se também que se obteve valores de dureza em torno de 60, para os compostos, independentemente do tipo de clone e dos tempos de vulcanização estudados.

Com o objetivo de investigar a morfologia dos compostos obtidos e a dispersão do negro de fumo na matriz de borracha natural foi realizada uma análise por MEV. Para o estudo,

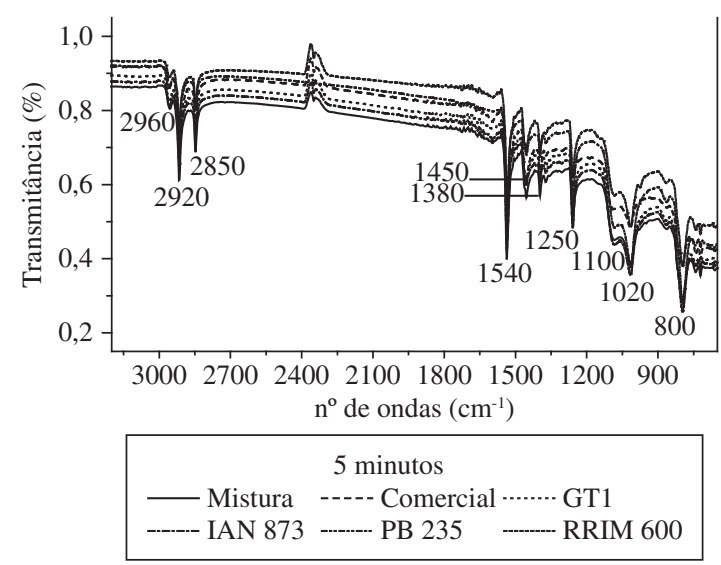

Figura 6. Curvas de FTIR dos compostos dos clones GT 1, IAN 873, PB 235 e RRIM 600, da mistura e da borracha comercial, com tempo de vulcanização de 5 minutos. 
Tabela 4. Dureza Shore A para os compostos de borracha natural dos diferentes clones.

\begin{tabular}{lccc}
\hline \multicolumn{1}{c}{ Amostras } & 5 minutos & 7 minutos & 9 minutos \\
\hline Mistura & $60 \pm 0,6$ & $61 \pm 0,6$ & $61 \pm 0,5$ \\
Comercial & $59 \pm 0,3$ & $60 \pm 0,5$ & $60 \pm 0,5$ \\
GT 1 & $61 \pm 0,6$ & $61 \pm 0,6$ & $62 \pm 0,6$ \\
IAN 873 & $61 \pm 0,6$ & $61 \pm 0,8$ & $61 \pm 0,4$ \\
PB 235 & $61 \pm 0,5$ & $62 \pm 0,0$ & $62 \pm 0,6$ \\
RRIM 600 & $61 \pm 0,6$ & $62 \pm 0,9$ & $62 \pm 0,5$ \\
\hline
\end{tabular}
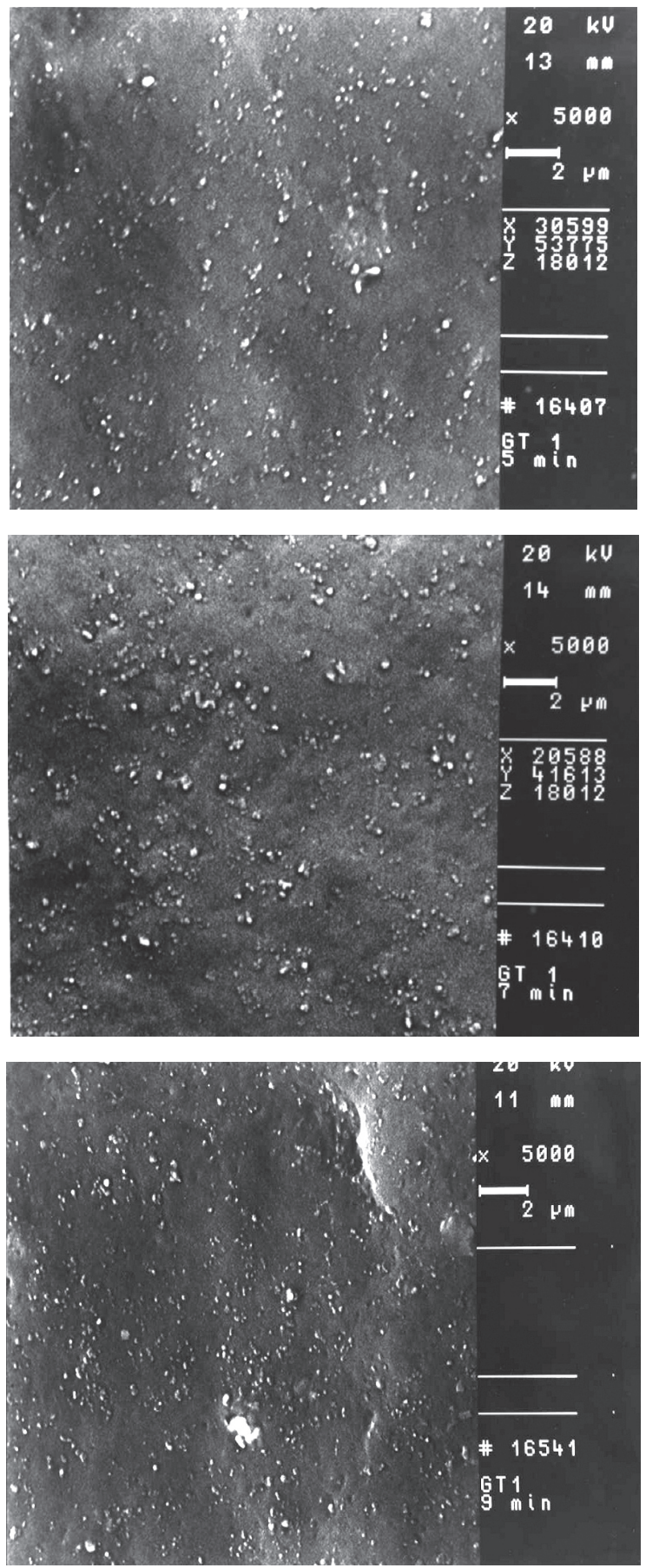

Figura 7. Micrografias obtidas por MEV da seção fraturada em nitrogênio líquido do composto do clone GT 1, para os tempos de vulcanização de 5, 7 e 9 minutos. 5000x. foram analisadas e comparadas as micrografias dos compostos dos clones GT 1, IAN 873, PB 235, RRIM 600, da mistura dos 4 clones e da borracha comercial do tipo GEB 1. A Figura 7 apresenta micrografias representativas da superfície criofraturada dos compostos obtidos em função do tempo de vulcanização, sendo apresentados os resultados para o estudo da morfologia das amostras para o clone GT 1. Vê-se que não há diferenças significativas relacionadas com os tempos de vulcanização estudados e que as partículas da carga (negro de fumo) estão bem distribuídas na matriz de borracha natural. As análises da superfície de fratura demonstram que não há diferença morfológica significativa entre as amostras dos diferentes clones, da mistura e da borracha comercial. Observou-se também que as partículas do negro de fumo estão bem distribuídas na matriz, provavelmente devido às boas condições de processamento utilizado, as quais levaram a obtenção de um material uniforme, sem falhas e uma mistura homogênea dos componentes da formulação, que é importante, visto que uma eventual heterogeneidade poderia afetar as propriedades estudadas.

\section{Conclusões}

O tempo de vulcanização e o tipo de clone não influenciaram na temperatura de transição vítrea dos compostos, com valores obtidos por DMA de cerca de $-62{ }^{\circ} \mathrm{C}$ e nos resultados ensaios de dureza, que apresentaram valores próximos de 60 .

A borracha natural dos clones estudados apresentou boa estabilidade térmica até cerca de $300{ }^{\circ} \mathrm{C}$, onde começa a degradação estrutural da borracha natural, que perde cerca de $50 \%$ da massa até a temperatura de $360{ }^{\circ} \mathrm{C}$. Não ocorreu perda de massa significativa na faixa da temperatura ambiente até cerca de $230{ }^{\circ} \mathrm{C}$, indicando que não ocorreu perda de massa relacionada à eliminação de água ou outros extrativos, conforme se observa pela análise de TG. Todos os compostos de borracha natural apresentaram uma morfologia compacta e homogênea com boa dispersão do negro de fumo, conforme analisadas nas micrografias das amostras crio-fraturadas e confirmada pelos picos estreitos obtidos pelas análises de DMA. Na análise térmica os valores obtidos para os compostos para a temperatura de transição vítrea pelas análises de DSC e DMA, foram na faixa de -57 a $-59{ }^{\circ} \mathrm{C}$ e -57 a $-66{ }^{\circ} \mathrm{C}$ respectivamente.

O clone RRIM 600 foi o que apresentou os melhores resultados da análise mecânica. Os clones estudados apresentaram nos diferentes tempos de vulcanização valores de resistência mecânica próximos aos dos valores encontrados para as amostras da borracha comercial. Todos os compostos de borracha estudados apresentaram as mesmas bandas de absorção nas análises de infravermelho, características do poli (cis-1,4-isopreno), não apresentando alterações entre os clones e para os diferentes tempos de vulcanização estudados. Os resultados obtidos neste trabalho mostraram que todos os 
clones estudados podem ser utilizados nas indústrias de artefatos de borracha separadamente ou na forma de mistura.

\section{Agradecimentos}

Os autores agradecem ao CNPq e à FAPESP pelo apoio financeiro e à Indústria Top Color pelo fornecimento da borracha comercial e dos aditivos.

\section{Referências Bibliográficas}

1. Dall' Antonia, A. C. - "Estudo do Desempenho Mecânico e Térmico de Compostos de Borracha Natura (NR) de Diferentes Clone”, Dissertação de Mestrado, Universidade de São Paulo/São Carlos, Brasil (2003).

2. Silva, J. Q.; Souza, M. I. T.; Gonçalves, P. S.; Aguiar, A. T. E.; Gouvêa, L. R. L. \& Pinotti, R. N. - Pesq. Agropec. Bras., 42, p.349 (2007).

3. Dall' Antonia, A. C. \& Martins, M. A. - Polímeros, 16, p.239 (2006).

4. Moreno, R. M. B.; Mattoso, L. H. C.; Job, A. E. \& Gonçalves, P. S. - Polímeros, 16, p.235 (2006).

5. Arope, A. B.; Nor A. B.M. \& Hua, T. P. - "Rubber Owner's Manual", Rubber Res. Inst., Kuala Lumpur (1983).

6. Benesi, J. F. C. - "Borracha Natural”, in: Anais do Ciclo de palestras sobre a heveicultura paulista, p.92, Barretos (1999).

7. Santos, M. A. - "Desenvolvimento de compósitos condutores elétricos de borracha natural com composto condutivo", Dissertação de Mestrado, Universidade Federal de São Carlos, Brasil (1999).

8. Costa, H. M.; Visconte, L. Y.; Nunes, R. C. R. \& Furtado, C. R. G. - Polímeros, 12, p.125 (2003).

9. Visconte, L. Y.; Martins, A. F.; Nunes, R. C. R. \& Suarez, J. C. M. - Polímeros, 11, p.76 (2001).

10. Pinheiro, E. G. - "Modelos Numéricos Aplicados à Vulcanização de Pneus", Dissertação de Mestrado, Escola Politécnica da Universidade de São Paulo, Brasil (2001).

11. Smith, W. F. - "Princípios de Ciência e Engenharia de Materiais", Ed. McGraw-Hill, Portugal (1998).

12. Wisniewski, A. - “Extrativismo Vegetal”, v.1. Belém (1978).

13. Oliveira, M. G. \& Soares, B. G. - Polímeros, 12, p.11 (2002).
14. Sombatsompop, N. - Polym.-Plast. Technol. Eng., 37, p.1, (1998).

15. Sae-oui, P.; Rakdee, C. \& Thanmathorn, P. - J. Appl. Polym. Sci., 83, p.2485 (2002).

16. Costa, H. M.; Visconte, L. L. Y. \& Nunes, R. C. R. - Polímeros, 12, p.102 (2003).

17. Fagundes, E.; Pierozan, N. J. \& Souza, A. A. - Revista Borracha Atual, 42, p.38 (2002).

18. American Society for Testing and Materials. ASTM D 412. "Standard Methods for Vulcanized Rubber and Thermoplastic Elastomers: Tension" (1998).

19. American Society for Testing and Materials. ASTM D 2240. "Standard Specification for: Durometer Hardness" (2002).

20. Brandrup, J. \& Immergut, E. H. (edits.), "Polymer Handbook", John Wiley and Sons, New York, (1975).

21. Oliveira, M. G. \& Soares, B. G. - Polímeros, 12, p.11 (2002).

22. Martins, A. F.; Visconte, L. L. Y. \& Nunes, R. C. R. - Polímeros, 12, p.295 (2002).

23. Martins, A. F.; Napolitano, B. A.; Visconte, L. L. Y.; Nunes, R. C. R. \& Furtado, A. M. - Polímeros, 12, p.147 (2002).

24. Canevarolo Jr., S. V. - "Análise Dinâmico-Mecânica Para Sistemas Poliméricos - Parte 1- O Amortecimento (tand)". ABPol, p.36 (1991).

25. Plepis, A. M. G. - "Caracterização Térmica de Polímeros por DSC", Monografia, Universidade de São Paulo. São Carlos, Brasil (1991).

26. Eschbach, J. M.; Roussel, D.; van de Sype, H.; Jacob, J. L. \& D’auzac, J. - Phisiology Végétale, 22, p.295 (1984).

27. Mano, E. B. \& Mendes, L. C. - “Introdução a Polímeros", Edgard Blücher, 2.ed. São Paulo (1999).

28. Rúvolo Filho, A. - "Físico-Química de Filmes de Borracha Clorada", Tese de Doutorado, Universidade de São Paulo, São Carlos, Brasil (1986).

29. Marinho, J. R. D. - "Microestrutura de cis-poliisopreno de Látices Naturais", Tese de Doutorado, Universidade Federal do Rio de Janeiro, Brasil (1992).

30. Brück, D. \& Dormagen, S. D. - Kutschuk Gummi Kunststoffe, 47, p.744 (1994).

Enviado: 27/11/07

Reenviado: 10/09/08

Aceito: 07/11/08 